Article

\title{
Cobalt Catalyst Reduction Thermodynamics in Fischer Tropsch: An Attainable Region Approach
}

\author{
Joshua Gorimbo *(D), Ralph Muvhiiwa *(D), Ephraim Llane and Diane Hildebrandt( \\ Institute for the Development of Energy for African Sustainability (IDEAS), College of Science, Engineering and \\ Technology, University of South Africa (UNISA), Florida Campus, c/o Christiaan de Wet \& Pioneer Avenue, \\ Johannesburg 1710, South Africa; llanemaphala@gmail.com (E.L.); hilded@unisa.ac.za (D.H.) \\ * Correspondence: joshuagorimbo@gmail.com (J.G.); r.muvhiiwa@gmail.com (R.M.); Tel.: +27-710894328 (J.G.); \\ +27-764263654 (R.M.)
}

Received: 28 October 2020; Accepted: 13 November 2020; Published: 17 November 2020

check for updates

\begin{abstract}
A fundamental understanding of the precise reduction reaction pathway of cobalt-based catalysts is a crucial piece of knowledge in terms of the Fischer-Tropsch Synthesis (FTS) reaction. The use of hydrogen $\left(\mathrm{H}_{2}\right)$ as the reduction agent results in a two-stage reduction of cobalt tetraoxide $\left(\mathrm{Co}_{3} \mathrm{O}_{4}\right)$ to cobalt oxide $(\mathrm{CoO})$ and then to metallic $\mathrm{Co}$. The objective of the present work is to apply the Thermodynamic Attainable Region (TAR) to cobalt catalyst reduction using $\mathrm{H}_{2}$ so as to gain better insight regarding the thermodynamics of reduction reaction. TAR space diagrams suggest that complete $\mathrm{Co}_{3} \mathrm{O}_{4}$ reduction is feasible through two reaction pathways. Thus, the observed AR results suggest that the temperature programmed reduction's (TPR) first reaction peak may be attributed to direct reduction of $\mathrm{Co}_{3} \mathrm{O}_{4} \rightarrow \mathrm{Co}$ and/or reduction to an intermediate compound $\mathrm{Co}_{3} \mathrm{O}_{4} \rightarrow \mathrm{CoO}$. The second peak is a result of the reduction of either of the cobalt oxides to $\mathrm{Co}\left(\mathrm{Co}_{3} \mathrm{O}_{4} \rightarrow \mathrm{Co}\right.$ or $\mathrm{CoO} \rightarrow \mathrm{Co})$.
\end{abstract}

Keywords: thermodynamic attainable region (TAR); temperature programmed reduction (TPR); cobalt based catalyst; cobalt reduction thermodynamics

\section{Introduction}

Catalyst reduction is an important process in Fischer Tropsch Synthesis (FTS) reactions. Fischer Tropsch practitioners perform a temperature programmed reduction (TPR) on a catalyst to establish the temperature at which reduction occurs [1]. The reduction temperature is usually a function of the metal used, the support and the catalyst synthesis method. Different approaches have been used to study catalysts during reduction reaction, and some researchers have used in situ characterization techniques to monitor cobalt catalyst phase changes during reduction.

Pioneering work done by Jacobs et al. [2] at the Center for Applied Energy (CAER) explored the chemical transformations occurring during cobalt based catalyst reduction in $\mathrm{H}_{2}$ using TPR-XANES/EXAFS [2]. The study gave insight into the nature of the cobalt species present along the trajectory of a standard TPR experiment, which showed the existence of a first peak between $200^{\circ} \mathrm{C}$ and $400{ }^{\circ} \mathrm{C}$, where reduction of $\mathrm{Co}_{3} \mathrm{O}_{4}$ to either $\mathrm{CoO}$ or $\mathrm{Co}$ occurs. The authors also reported that cobalt crystallite size changes during reduction as a function of temperature and the dependency on the strength of the catalyst support interaction with the cobalt oxide species [2]. Recently, several researchers have been using in-situ analysis to understand reaction pathways and behaviours, such as Kumar and fellow researchers who used a combined in-situ XRD and in situ XANES to study the reduction behaviour of a rhenium-promoted cobalt catalyst [3]. The study showed a typical two peak reduction profile, and indicated crystalline sizes and the Co-hcp/Co-fcc ratios at different temperatures. More advanced tools, which provide better penetration capability and brilliance with 
hard X-rays from a synchrotron source, are now employed to investigate catalyst reduction reaction under in-situ conditions and in a time-resolved manner.

Normal TPR experiments carried out with a Micromeritics Auto Chem II unit [4] or a Zeton-Altamira AMI-200 unit [2] (both of which employ a thermal conductivity detector (TCD)) only revealed two peaks, which correspond with $\mathrm{Co}_{3} \mathrm{O}_{4}$ reduction to $\mathrm{CoO}$, and subsequently $\mathrm{CoO}$ to Co. This speciation happens as a function of reduction temperature.

The reduction performance of the heterogeneous cobalt catalyst in $\mathrm{H}_{2}$ could also be analyzed using a thermodynamic approach. A novel Thermodynamic Attainable Region (TAR) approach that has previously been applied to reactor optimization [5] was applied in this study, in order to predict catalyst speciation. The Gibbs free energy $(\mathrm{G})$ minimization approach can be applied to show speciation direction in the TAR space. These TAR diagrams can be viewed as predictive tools that give insight into catalyst speciation in the reactor for any given conditions. In order to determine the optimum reduction condition, one needs to know how the changes in Gibbs free energy $(\Delta \mathrm{G})$ affects the catalyst speciation with any given condition. The AR method is a technique that can help build and optimize phase changes in a cobalt reduction system. The TAR is defined as the set of all possible outcomes that can be achieved for the system under consideration, using the fundamental processes operating within the system and which satisfies all constraints placed on the system [6].

The AR has also been extended to processes (rather than only reactors), and feed and products can be specified to achieve a specific goal [7]. The technique has been used to develop high-level design process flow sheets that represent the limit of what is thermodynamically achievable. The resulting process flow sheets convert raw material to desired products with efficient energy consumption, while operating as close as possible to reversibility [8]. A set of independent material balances are determined, and the AR is found in the space of extents of reaction [9]. This region represents the set of all possible outputs from all possible processes and can be useful in identifying desired processes $[5,8]$. This TAR is referred to as the Material Balance-Attainable Region (MB-AR). The MB-AR is used to obtain a TAR in a G-H space; we call this the Gibbs free energy-Enthalpy Attainable Region (G-H AR), which defines the heat and work requirements for all possible reaction processes. A typical G-H AR is shown in Figure 1.

G-H Attainable Region for $\mathrm{Co}_{3} \mathrm{O}_{4}$ reduction using $\mathrm{H}_{2}$

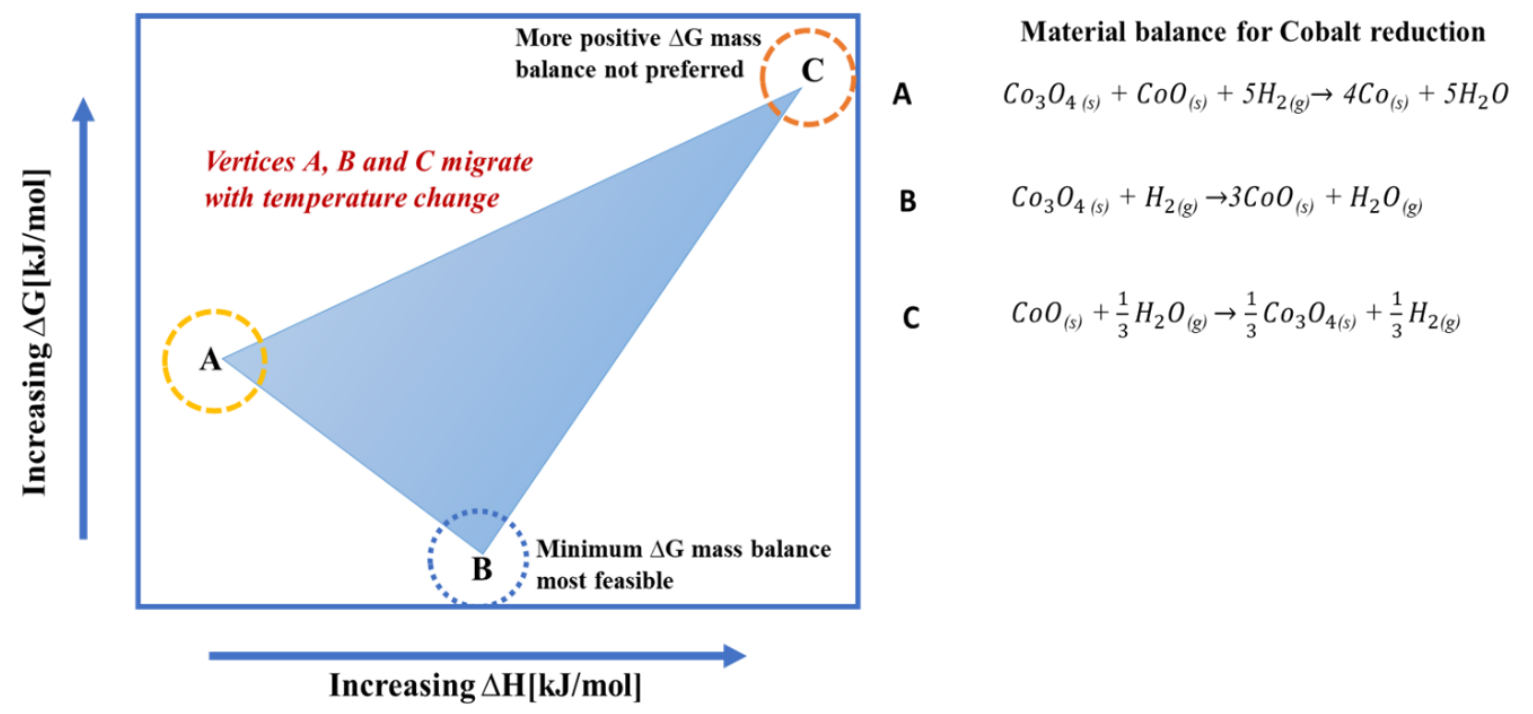

Figure 1. Typical G-H AR of the cobalt reduction system (points A, B and C show the boundary vertices of the G-H AR).

The method described in this research article for establishing optimum conditions for cobalt reduction thermodynamically is based on the determination of minimal $\mathrm{G}$ at different temperatures. 
This thermodynamic study should be useful for predicting optimum temperatures at ambient pressure for the desired phase. The thermodynamics of the precursor speciation is governed by the reduction gases used, and this tends to influence the activity, selectivity and catalyst life span.

\section{Materials and Methods}

\subsection{Temperature Programmed Reduction (TPR)}

TPR experiments of the 10\% Cobalt/Zeolite catalyst were carried out using a Micromeritics Auto Chem II unit (Norcross, GA, USA). The catalyst (approximately $50 \mathrm{mg}$ ) was placed in a quartz tubular reactor, fitted with a thermocouple for continuous temperature measurement. The reactor was heated in a furnace. Prior to the TPR measurement, the calcined catalyst was flushed with high-purity argon (99.999\% from African Oxygen Limited South Africa (Afrox, South Africa), at $200{ }^{\circ} \mathrm{C}$, for $30 \mathrm{~min}$, to remove water and/or any impurities. It was then cooled to ambient temperature. Thereafter, $5 \% \mathrm{H}_{2} / \mathrm{Ar}$ (African Oxygen Limited, South Africa) was introduced and the temperature was raised at a rate of $10^{\circ} \mathrm{C} / \mathrm{min}$ from 50 to $850^{\circ} \mathrm{C}$. The gas flow rate through the reactor was controlled by three Brooks mass flow controllers and maintained at $50 \mathrm{~mL} / \mathrm{min}$. The $\mathrm{H}_{2}$ consumption (TCD signal), as a function of temperature, was recorded. The results are shown in Figure 2. Generally, different catalyst supporters and promoters affect the TPR pattern.

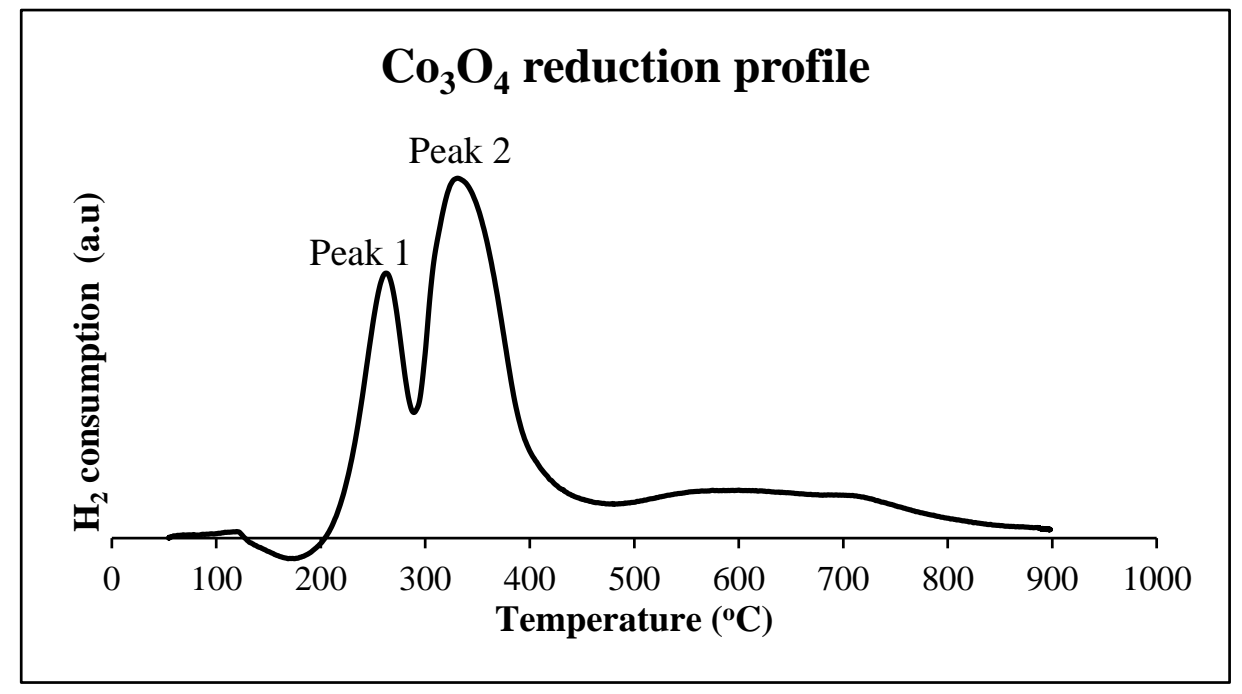

Figure 2. $\mathrm{H}_{2}$-Temperature programmed reduction profile for $10 \% \mathrm{Co} /$ Zeolite. (Zeolite type used is Clinoptilolite.).

For any given loading of cobalt on the catalyst, 1 mole of $\mathrm{Co}_{3} \mathrm{O}_{4}$ spinel will produce 4 moles of water during reduction-Equation (1).

$$
\mathrm{H}_{2} \text { reduction } \mathrm{Co}_{3} \mathrm{O}_{4}+4 \mathrm{H}_{2} \rightarrow 3 \mathrm{Co}+4 \mathrm{H}_{2} \mathrm{O}
$$

The temperature programmed profile suggests the existence of two elementary reactions. The first corresponds to complete reduction of $\mathrm{Co}_{3} \mathrm{O}_{4}$ to $\mathrm{CoO}$, which consumes one hydrogen molecule-Equation (2).

$$
\text { Peak } 1 \quad \mathrm{Co}_{3} \mathrm{O}_{4}+\mathrm{H}_{2} \rightarrow 3 \mathrm{CoO}+\mathrm{H}_{2} \mathrm{O}
$$

The predicted second elementary reaction involves the consumption of hydrogen molecules to make active Co-Equation (3).

$$
\text { Peak } 2 \mathrm{CoO}+\mathrm{H}_{2} \rightarrow \mathrm{Co}+\mathrm{H}_{2} \mathrm{O}
$$


The cobalt catalysts generally exhibit two peaks in TPR: a sharp first peak and a second broader peak at a higher temperature.

\subsection{Attainable Region Approach (AR)}

The method to obtain the MB-AR described here is similar to the one described by Okonye et al. for the methanol synthesis process [9]. In order to determine the MB-AR for the cobalt system, one should initially come up with three possible material balances, as given by Equations (1)-(3) and determine what the favoured products would be for a system involving these material balances under different conditions. These three material balances (reaction 1,2 and 3) have traditionally been used to define the reactions taking place during the cobalt reduction process.

\subsection{Achieving the $M B-A R$ in Extent of Reaction Space}

Material Balance-Attainable Region in the extent space is the plot of the region containing all possible sets of the extent of the reactions or material balances. Exact chemical reactions are not always known in a reactive system; thus, it is useful to use the concept of independent reactions or material balances. The cobalt system studied has five chemical species, namely $\mathrm{Co}_{3} \mathrm{O}_{4}, \mathrm{H}_{2}, \mathrm{Co}, \mathrm{H}_{2} \mathrm{O}, \mathrm{CoO}$. These are used to determine the independent material balances. The independent material balances are obtained in a similar manner as that used to obtain the independent reactions. In fact, independent material balances and independent reactions can be used interchangeably for reactions. The matrix algebra method developed by Yin (1989) [10] to determine independent reactions was used in this work. The system is arranged into a matrix function (as shown in Table 1) and Gaussian elimination is applied (as shown in Table 2) to find the independent material balances. This is achieved by trying to obtain a single ' 1 ' in each column (in any row, but not the same row) and making all other entries zero.

Table 1. Atomic matrix form of the cobalt system compounds.

\begin{tabular}{cccc}
\hline Co & $\mathbf{H}$ & $\mathbf{O}$ & Compounds \\
\hline 3 & 0 & 4 & $\mathrm{Co}_{3} \mathrm{O}_{4}$ \\
1 & 0 & 0 & $\mathrm{Co}$ \\
0 & 2 & 0 & $\mathrm{H}_{2}$ \\
1 & 0 & 1 & $\mathrm{CoO}$ \\
0 & 2 & 1 & $\mathrm{H}_{2} \mathrm{O}$ \\
\hline
\end{tabular}

Table 2. Gaussian elimination to get independent material balances for the cobalt system.

\begin{tabular}{cccc}
\hline Co & $\mathbf{H}$ & $\mathbf{O}$ & Compounds \\
\hline 0 & 0 & 0 & $\mathrm{Co}_{3} \mathrm{O}_{4}-3 \mathrm{Co}-4\left(\mathrm{H}_{2} \mathrm{O}-\mathrm{H}_{2}\right)$ \\
1 & 0 & 0 & $\mathrm{Co}$ \\
0 & 1 & 0 & $1 / 2 \mathrm{H}_{2}$ \\
0 & 0 & 0 & $\mathrm{CoO}-\mathrm{Co}_{2}\left(\mathrm{H}_{2} \mathrm{O}-\mathrm{H}_{2}\right)$ \\
0 & 0 & 1 & $\mathrm{H}_{2} \mathrm{O}-\mathrm{H}_{2}$ \\
\hline
\end{tabular}

The two independent mass balances are obtained when all components $(\mathrm{Co}, \mathrm{H}$, and $\mathrm{O})$ equal zero and are given by Equations (4) and (5), where $\varepsilon$ is the extent of reaction. This means that, at any given point in time, the amount of product and the remaining reactant can be determined.

$$
\begin{gathered}
\mathrm{Co}_{3} \mathrm{O}_{4}(\mathrm{~s})+4 \mathrm{H}_{2}(\mathrm{~g}) \rightarrow 3 \mathrm{Co}_{(\mathrm{s})}+4 \mathrm{H}_{2} \mathrm{O}_{(\mathrm{g})} \quad \varepsilon_{1} \\
\mathrm{CoO}(\mathrm{s})+\mathrm{H}_{2}(\mathrm{~g}) \rightarrow \mathrm{Co}(\mathrm{s})+\mathrm{H}_{2} \mathrm{O}_{(\mathrm{g})} \quad \varepsilon_{2}
\end{gathered}
$$

The above independent material balances can be expressed in terms of extent of reaction. This was used to determine the MB-AR in extent space. 
Mole balances in terms of extent of reactions are used to determine the feasible region, where the number of moles of each component is either zero or a positive number. The obtained feasible region is thus the MB-AR in the extent space. Table 3 shows that the MB-AR is a function of initial conditions, i.e., initial moles of key components. The MB-AR for the ratios of feed and different species are provided. However, for the scope of this research analysis, two components are specified as feed: $\mathrm{N}^{\mathrm{O}} \mathrm{Co}_{3} \mathrm{O}_{4}=1$ and $\mathrm{N}^{\mathrm{O}} \mathrm{H}_{2}=$ (varied between 0 and excess).

Table 3. Stoichiometric material balance showing extent of reactions.

\begin{tabular}{ccc}
\hline Initial Moles & Change & Moles \\
\hline $\mathrm{N}^{\mathrm{o}} \mathrm{Co}_{3} \mathrm{O}_{4}$ & $-\varepsilon_{1}$ & $\mathrm{~N}^{\mathrm{o}} \mathrm{Co}_{3} \mathrm{O}_{4}-\varepsilon_{1} \geq 0$ \\
$\mathrm{~N}^{\mathrm{O}} \mathrm{H}_{2}$ & $-4 \varepsilon_{1}-\varepsilon_{2}$ & $\mathrm{~N}^{\mathrm{o}} \mathrm{H}_{2}-4 \varepsilon_{1}-\varepsilon_{2} \geq 0$ \\
$\mathrm{~N}^{\mathrm{o}} \mathrm{Co}$ & $+3 \varepsilon_{1}+\varepsilon_{2}$ & $\mathrm{~N}^{\mathrm{o}} \mathrm{Co}_{\mathrm{o}}+3 \varepsilon_{1}+\varepsilon_{2} \geq 0$ \\
$\mathrm{~N}^{\mathrm{O}} \mathrm{H}_{2} \mathrm{O}$ & $+4 \varepsilon_{1}+\varepsilon_{2}$ & $\mathrm{~N}^{\mathrm{O}}{ }_{\mathrm{H}_{2} \mathrm{O}}+4 \varepsilon_{1}+\varepsilon_{2} \geq 0$ \\
$\mathrm{~N}^{\mathrm{o}} \mathrm{CoO}$ & $-\varepsilon_{2}$ & $\mathrm{~N}^{\mathrm{O}} \mathrm{CoO}-\varepsilon_{2} \geq 0$ \\
\hline
\end{tabular}

We used the Matlab Mupad (Natick, MA, USA, Matlab version R2018a) functions to solve the inequalities in Table 3 and thus to obtain the MB-AR. The Mupad function also allows us to determine the vertices of the MB-AR in terms of extents $\left(\varepsilon_{1}, \varepsilon_{2}\right)$. The vertices are crucial, because the minimum $G$ in the G-H space at any given conditions is found at one of the vertices (Matlab scripts and further description of the methodology are given as supplementary material).

\subsection{Plotting the AR in a G-H Space}

The AR in a G-H space (G-H AR) can be constructed from the MB-AR, using the thermodynamic properties of Gibbs free energy and enthalpy at a specific temperature and pressure. Gibbs free energy and enthalpy represent work potential and minimum energy requirements of the process or reaction, respectively. Positive values mean work and energy need to be supplied to the process, while negative values mean work and energy are released from the process. The standard Gibbs free energy and enthalpy of formation for our two independent material balances are obtained at $25^{\circ} \mathrm{C}$ and 1 bar $[11,12]$, and are given by Equations (6) and (7).

$$
\begin{gathered}
\mathrm{Co}_{3} \mathrm{O}_{4}(\mathrm{~s})+4 \mathrm{H}_{2}(\mathrm{~g}) \rightarrow 3 \mathrm{Co}_{(\mathrm{s})}+4 \mathrm{H}_{2} \mathrm{O}_{(\mathrm{g})}, \Delta \mathrm{H}_{1}=-57.1 \mathrm{~kJ} / \mathrm{mol} ; \Delta \mathrm{G}_{1}=-140.4 \mathrm{~kJ} / \mathrm{mol} \\
\mathrm{CoO}_{(\mathrm{s})}+\mathrm{H}_{2}(\mathrm{~g}) \rightarrow \mathrm{Co}_{(\mathrm{s})}+\mathrm{H}_{2} \mathrm{O}_{(\mathrm{g})}, \Delta \mathrm{H}_{2}=-3.93 \mathrm{~kJ} / \mathrm{mol} ; \Delta \mathrm{G}_{2}=-14.4 \mathrm{~kJ} / \mathrm{mol}
\end{gathered}
$$

The overall $\Delta \mathrm{G}$ and $\Delta \mathrm{H}$ as functions of extent of reactions shown in Equations (8) and (9) are simply the addition of $\Delta \mathrm{H}$ and $\Delta \mathrm{G}$ in relation to the respective extents of the two independent material balances at the given conditions of temperature and pressure.

$$
\begin{aligned}
\Delta H & =\varepsilon_{1} \Delta H_{1}+\varepsilon_{2} \Delta H_{2} \\
\Delta G & =\varepsilon_{1} \Delta G_{1}+\varepsilon_{2} \Delta G_{2}
\end{aligned}
$$

The extents at the limit of the MB-AR will form the boundaries of the G-H AR. The $\Delta \mathrm{H}$ at various temperatures were calculated using the heat capacity of the species involved, using Equation (10) and the respective heat capacity (Cp) function and constants, where provided by Chase (1998) [11].

$$
\Delta \mathrm{H}=\Delta \mathrm{H}^{\mathrm{o}}+\Delta \mathrm{Cp}\left(\mathrm{T}-\mathrm{T}_{\mathrm{o}}\right)
$$

Both $\mathrm{CoO}$ and $\mathrm{Co}_{3} \mathrm{O}_{4}$ compounds used in this analysis can be assumed to form by adding $\mathrm{O}_{2}$ to Co, according to Equations (11) and (12), as described by Holmes et al. [13].

$$
\mathrm{Co}_{(\mathrm{s})}+\frac{1}{2} \mathrm{O}_{2}(\mathrm{~g}) \rightarrow \mathrm{CoO}_{(\mathrm{s})}
$$




$$
3 \mathrm{Co}_{(\mathrm{s})}+2 \mathrm{O}_{2}(\mathrm{~g}) \rightarrow \mathrm{Co}_{3} \mathrm{O}_{4}(\mathrm{~s})
$$

The molar Gibbs free energy of an ideal gas is dependent on partial pressures, hence the $\Delta \mathrm{G}$ as a function of temperature for the cobalt compounds $\left(\mathrm{CoO}\right.$ and $\left.\mathrm{Co}_{3} \mathrm{O}_{4}\right)$ were obtained using Equation (13), where the partial pressure of $\mathrm{O}_{2}$ was used in the equation. Assuming ideal gas behavior: $\mathrm{k}$ is the equilibrium constant (which is a measure of the ratio of the concentrations of products to the concentrations of reactants); $\mathrm{R}$ is the ideal gas constant; $\mathrm{T}$ represents temperature; and $\mathrm{n}$ is the number of moles of gas.

$$
\Delta \mathrm{G}=\Delta \mathrm{G}^{\mathrm{o}}+\mathrm{nRT} \mathrm{T}^{*} \ln \mathrm{k}
$$

\subsection{Importance of the G-H AR in Understanding Cobalt Reduction Reaction}

Kinetics play an important role in achieving the active $\mathrm{Co}(\mathrm{S})$ state during the reduction processes from its respective cobalt oxides. However, understanding the thermodynamic limits of the reduction process can guide how kinetics can be altered/directed to achieve certain products. Many researchers focus their research on trying to improve the kinetics of the reduction process, but it is important to know that the extent to which the kinetics can be improved is governed by thermodynamic limits. The G-H AR helps to define these thermodynamic limits. The cobalt reduction process is a fast-continuous process and the researchers assumes that it reaches equilibrium quick enough that it can be related to the thermodynamic G-H AR at particular conditions. It must be clear that the G-H AR will help show the expected thermodynamic product composition and possible thermodynamic reaction pathway at specific conditions and not how fast it will get to the products. A reaction pathway can be thermodynamically feasible, but it may be kinetically difficult to follow the specific thermodynamic pathway. Thus, kinetics and catalysts have played an important role in using alternative routes to the preferred thermodynamically route to get to products. However, these alternative routes fall within the boundaries of the G-H ARs at the conditions applied and cannot be outside.

The more negative the Gibbs free energy the greater the driving forces to achieve products and the minimum Gibbs free energy point on a G-H AR shows the most thermodynamically favoured set of products. Different sets of products may be present at minimum $\mathrm{G}$ and at these conditions mixing becomes important in getting the final composition. This situation is important when designing a reacting system as it can allow one to understand the separation mechanism required to achieve a certain product composition. Because we assume that the cobalt reduction process is fast, a snapshot to mimic a specific state of the reaction at defined set of operating conditions can be defined by thermodynamics. The G-H ARs only show the thermodynamic limits that can be achieved at equilibrium. Most importantly the results of the cobalt system attainable region presented here was to determine the reduction alternatives routes on what is thermodynamically feasible and what is not, but not necessarily to include kinetics, cost measures etcetera. More so, these thermodynamic limits can be defined irrespective of whether the reaction is in a batch or continuous reactor because it is assumed fast kinetics to reach equilibrium have been assumed.

\section{Results}

\subsection{Material Balance Attainable Region}

The MB-AR is a function of initial feed composition. It is therefore crucial to investigate how initial composition affects MB-AR for our system. $\mathrm{H}_{2}$ is usually the common feed material used to reduce $\mathrm{Co}_{3} \mathrm{O}_{4}$ to make the active $\mathrm{Co}$. The researchers are interested in a system with a feed of $\mathrm{Co}_{3} \mathrm{O}_{4}$ and $\mathrm{H}_{2}$, because this resembles the typical TPR process in FTS. This section will therefore explore these two compounds as feed, at different compositions. To start with, the different combinations of feed materials were investigated where a basis of 1 mole of $\mathrm{Co}_{3} \mathrm{O}_{4}(\mathrm{~s})$ was used for different amounts of $\mathrm{H}_{2}(\mathrm{~g})$ supplied. Figure 3a-d shows different results obtained by changing the $\mathrm{H}_{2}$ amount in the feed combination of the system. The initial/feed composition vector is represented by nox $=\left[\mathrm{Co}_{3} \mathrm{O}_{4} ; \mathrm{H}_{2} ;\right.$ $\left.\mathrm{H}_{2} \mathrm{O} ; \mathrm{CoO} ; \mathrm{Co}\right]$. 


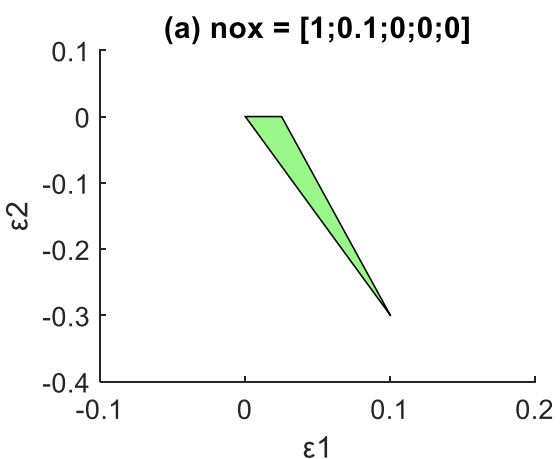

(c) nox $[1 ; 2 ; 0 ; 0 ; 0]$

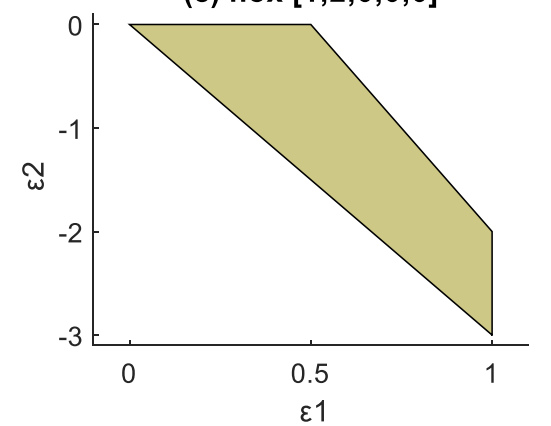

(b) $\operatorname{nox}=[1 ; 1 ; 0 ; 0 ; 0]$

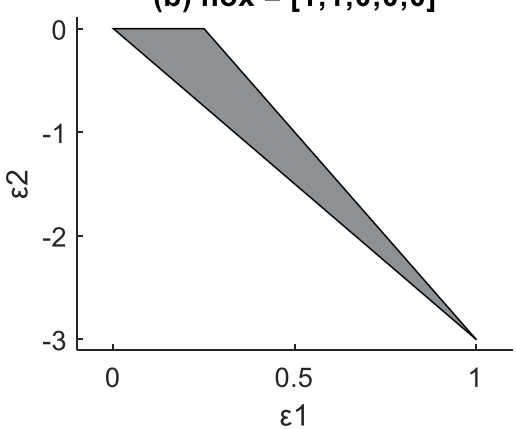

(d) $\operatorname{nox}[1 ; 4 ; 0 ; 0 ; 0]$

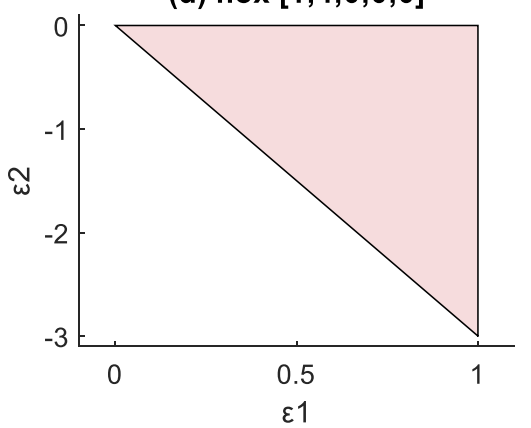

Figure 3. Change in MB-AR in extent space for a feed 1 mole $\mathrm{Co}_{3} \mathrm{O}_{4}$ when the $\mathrm{H}_{2}$ supplied is increased, (a) 0.1 moles, (b) 1 mole, (c) 2 mole, (d) 4 moles. (Figure 3d) was used to obtain the G-H AR.

Figure 3 also confirms that there are three vertices that form the boundaries of the MB-AR for the cobalt system, when two components are specified as feed. Each corner/vertex represents a different composition. This is true for the initial feed considered. However, it is possible for the same system to have four vertices if the initial amount is varied or if one of the components is limiting.

Figure 3 shows how changes in the amount of $\mathrm{H}_{2}$ fed affect the MB-AR: the amount of $\mathrm{H}_{2}$ was increased from 0.1 mole (Figure 3a) to 4 moles (Figure 3d). Increasing the $\mathrm{H}_{2}$ feed while maintaining a feed of 1 mole $\mathrm{Co}_{3} \mathrm{O}_{4}$ changes the shape of MB-AR, while also expanding its region. The MB-AR in Figure $3 b-d$ shows the point at $\varepsilon_{1}=1$, when all $\mathrm{Co}_{3} \mathrm{O}_{4}$ is reduced. Adding more than 4 moles of $\mathrm{H}_{2}$ does not change the shape of the mass balance MB-AR shown in Figure $3 \mathrm{~d}$.

Figure 4 is similar to Figure $3 \mathrm{~d}$ and gives the MB-AR case that shows the overall reduction of the $\mathrm{Co}_{3} \mathrm{O}_{4}$ compound with $\mathrm{H}_{2}$ to $\mathrm{Co}$. The three vertices in the respective MB-AR are obtained $\left(\varepsilon_{1}, \varepsilon_{2}\right)=$ Feed $(0,0), A(1,0)$ and $B(1,-3)$, which form the limits of the MB-AR. These vertices are used together with the Gibbs free energy and enthalpies to plot the G-H AR in Figure 5. 


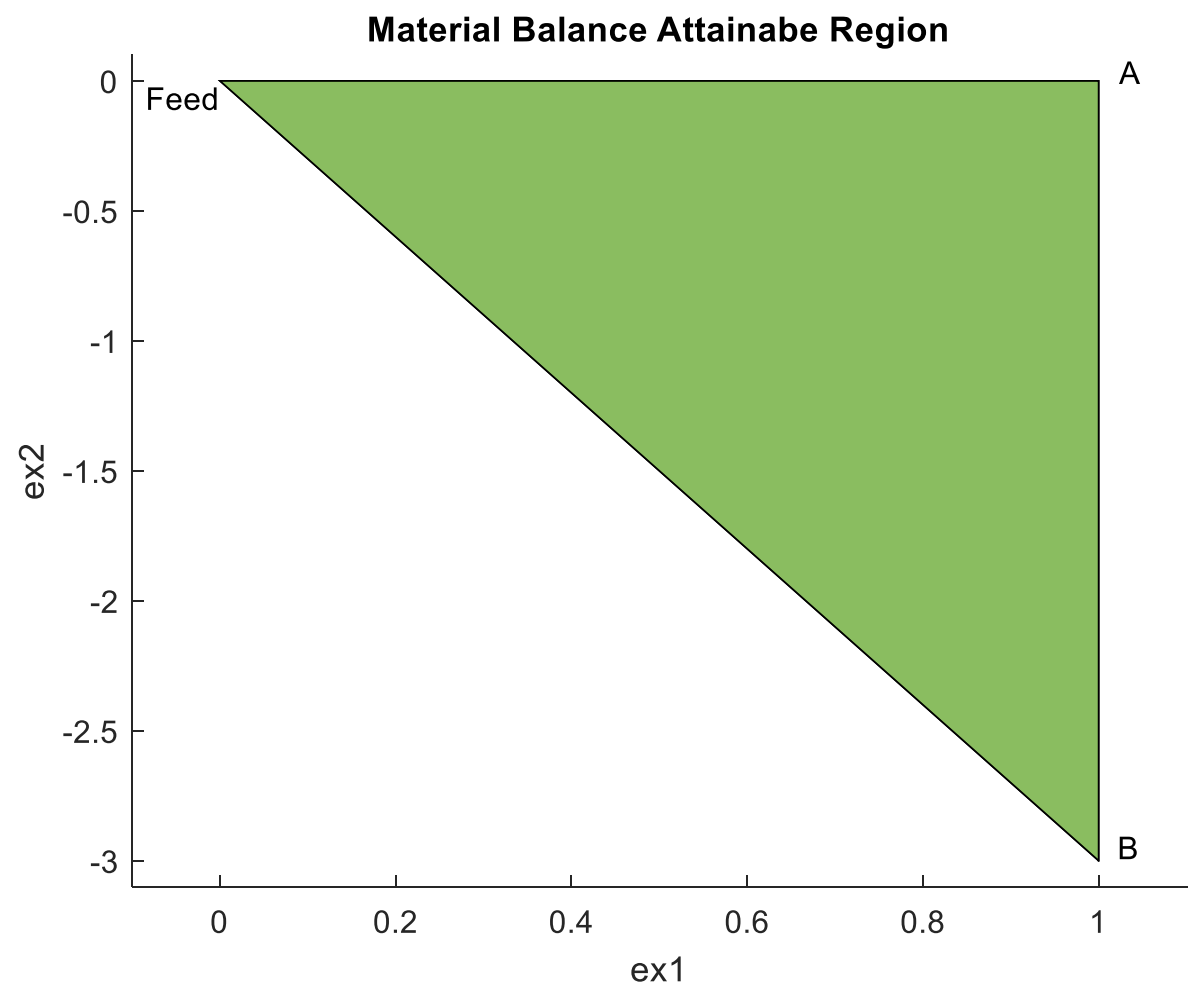

Figure 4. MB-AR in extent space for a feed 1 mole $\mathrm{Co}_{3} \mathrm{O}_{4}$ and 4 moles $\mathrm{H}_{2}$.

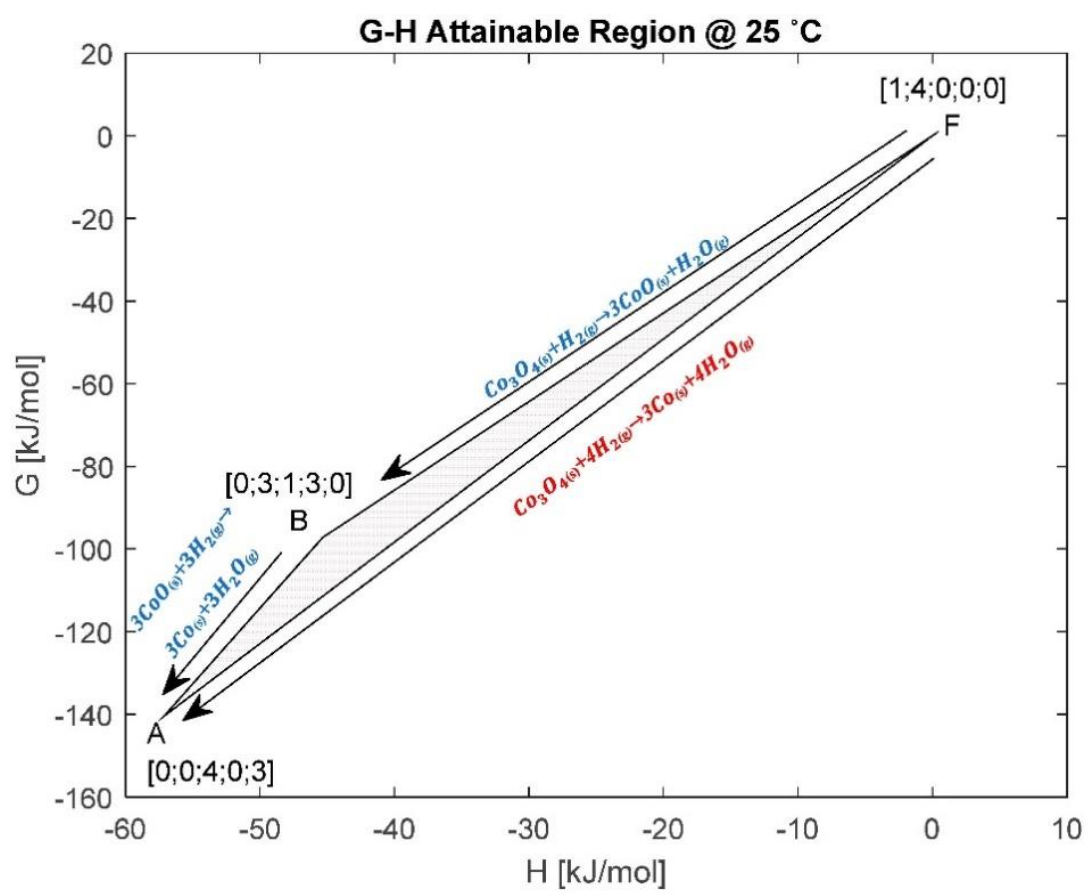

Figure 5. G-H AR for the cobalt system at $25^{\circ} \mathrm{C}$.

\subsection{G-H Attainable Region at $25^{\circ} \mathrm{C}$}

Figure 5 is obtained by transforming the MB-AR in Figure 4 to the G-H space. The composition at each vertex is represented as follows: $\mathrm{Co}_{3} \mathrm{O}_{4} ; \mathrm{H}_{2} ; \mathrm{H}_{2} \mathrm{O} ; \mathrm{CoO}$ : Co. Figure 5 introduces the G-H AR and shows that it is bound by three vertices. The material balances are given in Equations (14)-(16). This also assumes that the zeolite support on the cobalt does not take part in the reactions. Gibbs free energy gives the energy associated with a chemical reaction that can be used to do work and form 
products in their most thermodynamically stable state. In Figure 4 , the standard $\Delta \mathrm{G}$ and $\Delta \mathrm{H}$ for material balance $\mathrm{A}$ and $\mathrm{B}$ are negative, which means that the reactions produce work and are exothermic. The more negative the $\Delta \mathrm{G}$, the more spontaneous the reaction is. The reduction of $\mathrm{Co}_{3} \mathrm{O}_{4}$ with $\mathrm{H}_{2}$ to Co (Equation (14)) is more thermodynamically favourable, as it exists at minimum Gibbs free energy (minimum G) on the G-H AR at $25{ }^{\circ} \mathrm{C}$. The G-H AR shows that $\mathrm{Co}_{3} \mathrm{O}_{4}$ can be thermodynamically reduced to $\mathrm{Co}$ or $\mathrm{CoO}$ without the need for work addition, as shown by reaction $\overrightarrow{F A}$ and $\overrightarrow{B A}$, respectively, in Figure 5. The G-H AR suggest that the reduction to Co can take place at $25{ }^{\circ} \mathrm{C}$ when both cobalt species $\left(\mathrm{CoO}\right.$ and $\left.\mathrm{Co}_{3} \mathrm{O}_{4}\right)$ are present in the reacting system. However, it is also important to note that a reaction may be thermodynamically feasible at $25^{\circ} \mathrm{C}$, but it may take a long time to occur due to kinetic barriers.

$$
\begin{aligned}
& \text { Feed (F) Molar feed }=\mathrm{Co}_{3} \mathrm{O}_{4}(\mathrm{~s})+4 \mathrm{H}_{2}(\mathrm{~g}) \\
& \overrightarrow{F A} \quad \mathrm{Co}_{3} \mathrm{O}_{4}(\mathrm{~s})+4 \mathrm{H}_{2}(\mathrm{~g}) \rightarrow 3 \mathrm{Co}_{(\mathrm{s})}+4 \mathrm{H}_{2} \mathrm{O}_{(\mathrm{g})}, \Delta \mathrm{H}=-57.1 \mathrm{~kJ} / \mathrm{mol} ; \Delta \mathrm{G}=-140.4 \mathrm{~kJ} / \mathrm{mol} \\
& \overrightarrow{F B} \quad \mathrm{Co}_{3} \mathrm{O}_{4}(\mathrm{~s})+\mathrm{H}_{2}(\mathrm{~g}) \rightarrow 3 \mathrm{CoO}(\mathrm{s})+\mathrm{H}_{2} \mathrm{O}_{(\mathrm{g})}, \Delta \mathrm{H}=-45.1 \mathrm{~kJ} / \mathrm{mol} ; \Delta \mathrm{G}=-97.2 \mathrm{~kJ} / \mathrm{mol} \\
& \overrightarrow{B A} 3 \mathrm{CoO}_{(\mathrm{s})}+3 \mathrm{H}_{2}(\mathrm{~g}) \rightarrow 3 \mathrm{Co}_{(\mathrm{s})}+3 \mathrm{H}_{2} \mathrm{O}_{(\mathrm{g})}, \Delta \mathrm{H}=-12.0 \mathrm{~kJ} / \mathrm{mol} ; \Delta \mathrm{G}=-43.2 \mathrm{~kJ} / \mathrm{mol}
\end{aligned}
$$

When comparing the $\Delta G$ s for the thermodynamic reactions $\overrightarrow{F A}$ and $\overrightarrow{F B}$, it is clear that, thermodynamically, the products of reaction $\overrightarrow{F A}$ will dominate the system, despite the $\Delta \mathrm{G}$ of material balance $\overrightarrow{F B}$ also being negative. This is because the $\Delta \mathrm{G}$ for reaction $\overrightarrow{F A}$ is more negative and it exists at the system's minimum G, where the products are more stable. However, it is important to note that the composition at $\mathrm{A}$ can be archived through two separate routes: (i) directly via $\overrightarrow{F A}$, as shown in Equation (14); (ii) or via $\overrightarrow{F B}$ then $\overrightarrow{B A}$, using Equations (15) and (16), respectively. According to Hess' law, the energy requirements for a chemical process are the same, irrespective of the pathway or steps taken to make the product composition. This means that $\Delta \mathrm{H}$ and $\Delta \mathrm{G}$ for the composition at $\mathrm{A}$ will always be the same for the two routes. In other words, combining Equations (15) and (16) should give Equation (14). However, the choice of the specific route taken in the reacting system will be defined by reaction kinetics, available driving force to make the products at equilibrium, reactor type and the reaction temperature.

\subsection{G-H Attainable Region at Higher Temperatures}

$\mathrm{Co}_{3} \mathrm{O}_{4}$ is usually reduced to make active $\mathrm{Co}$ in the FTS at temperatures between $200-500{ }^{\circ} \mathrm{C}$ [14] depending on the type of catalyst and support used. $\mathrm{Co}_{3} \mathrm{O}_{4}$ is reduced with $\mathrm{H}_{2}$ in the reactor before the syngas is introduced. First, it is necessary to see how the G-H AR changes to show the respective thermodynamically feasible phases in this temperature range. It is also important to see how the product spectrum, heat and work requirements of the system change when the temperature is increased.

When the temperature is increased to $200^{\circ} \mathrm{C}$, as shown by the G-H AR in Figure 6, the first thing noted is that the possibility of making $\mathrm{Co}$ directly from $\mathrm{Co}_{3} \mathrm{O}_{4}$ reduction is still at the minimum $\mathrm{G}$ of the system. This does not require any work addition, and the respective $\Delta G$ values are shown in Table 4. This may be a possible explanation for the occurrence of the first peak observed in Figure 2 at about $250{ }^{\circ} \mathrm{C}$, when $\mathrm{Co}_{3} \mathrm{O}_{4}$ can be kinetically reduced by $\mathrm{H}_{2}$ to $\mathrm{Co}$. However, at about $200{ }^{\circ} \mathrm{C}$, the $\Delta \mathrm{G}$ for material balance $\overrightarrow{F B}$ also moves closer to minimum $\Delta \mathrm{G}$, which increases the likelihood of products for this material balance being present in the system (although not yet at minimum $G$ ). Thus, the observed AR results suggest that the first peak may be attributed to either: direct reduction of $\mathrm{Co}_{3} \mathrm{O}_{4}$ to $\mathrm{Co}$ through material balance in Equation (1); or reduction of $\mathrm{Co}_{3} \mathrm{O}_{4}$ to $\mathrm{CoO}$ through material balance in Equation (15). This is where the notion of reaction pathways comes in, where $\overrightarrow{F B}$ shows a steeper gradient, and it is hypothesized that it is the preferred route compared to $\overrightarrow{F A}$. If we assume that the reaction follows the boundaries of the G-H AR as its pathway, the pathway that offers the 
steepest gradient from the feed is likely to be most favoured towards the minimum G. This is because a steeper gradient is hypothesized to be the route in which the system has the most available driving force to make products or intermediate products. Thus, route $\overrightarrow{F B}$ would most likely represent peak 1 .

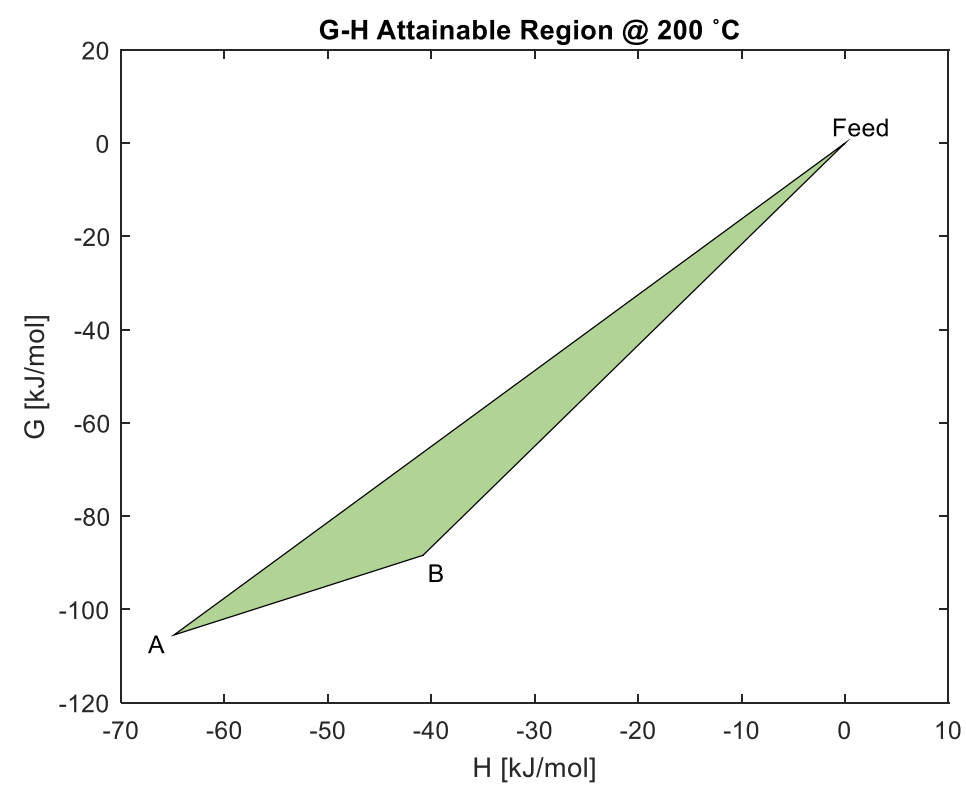

Figure 6. Analysis of predicted material balances using the G-H AR for the cobalt system at $200{ }^{\circ} \mathrm{C}$.

Table 4. $\Delta \mathrm{G}$ and $\Delta \mathrm{H}$ for the material balances at various temperatures of the G-H AR (Thermodynamic data obtained from references 11 and 15.) [11,15].

\begin{tabular}{cccc}
\hline & Material Balance & $\Delta \mathbf{H ~ k J} / \mathbf{m o l}$ & $\Delta \mathrm{G} \mathrm{kJ} / \mathbf{m o l}$ \\
\hline \multirow{2}{*}{$\mathbf{2 5}{ }^{\circ} \mathrm{C}$} & $\mathrm{A}$ & -233.05 & -174.6 \\
& $\mathrm{~B}$ & -89.33 & -105.8 \\
& Feed & 0 & 0 \\
\hline \multirow{2}{*}{$\mathbf{2 0 0}{ }^{\circ} \mathrm{C}$} & $\mathrm{A}$ & -64.86 & -105.5 \\
& $\mathrm{~B}$ & -40.8 & -88.39 \\
\hline \multirow{2}{*}{$\mathbf{3 2 0}{ }^{\circ} \mathrm{C}$} & $\mathrm{A}$ & -70.58 & -82.34 \\
& $\mathrm{~B}$ & -39.59 & -82.5 \\
\hline \multirow{2}{*}{$\mathbf{4 0 0}{ }^{\circ} \mathrm{C}$} & $\mathrm{A}$ & -70.94 & -66.37 \\
& $\mathrm{~B}$ & -38.51 & -78.61 \\
\hline \multirow{2}{*}{$\mathbf{6 0 0}{ }^{\circ} \mathrm{C}$} & $\mathrm{A}$ & -83.91 & -28.04 \\
& $\mathrm{~B}$ & -41.31 & -68.81 \\
\hline \multirow{2}{*}{$\mathbf{8 0 0}{ }^{\circ} \mathrm{C}$} & $\mathrm{A}$ & -95.44 & 9.44 \\
& $\mathrm{~B}$ & -46.99 & -59.62 \\
\hline
\end{tabular}

The scenario shown in Figure 7 shows that the $\Delta \mathrm{G}$ for material balances $\overrightarrow{F A}$ and $\overrightarrow{F B}$ are the same, $\Delta \mathrm{G}=-82 \mathrm{~kJ} / \mathrm{mole}$ at $320^{\circ} \mathrm{C}$, as shown in Equations (17) and (18). Equation (19) shows the exothermic reaction $\overrightarrow{B A}$, where $\mathrm{CoO}$ is directly reduced to $\mathrm{Co}$ with no work addition. All these reactions are at minimum $\triangle \mathrm{G}$ and any of the two material balances is likely to happen directly from the feed in the system, and then influence the product spectrum. A mixture of products from the two material balances is possible. In typical systems such as gasification, separation of products can be achieved through mixing, where the $\Delta \mathrm{Gs}$ are similar.

$$
\text { FA } \mathrm{Co}_{3} \mathrm{O}_{4}(\mathrm{~s})+4 \mathrm{H}_{2}(\mathrm{~g}) \rightarrow 3 \mathrm{Co}_{(\mathrm{s})}+4 \mathrm{H}_{2} \mathrm{O}_{(\mathrm{g})}, \Delta \mathrm{H}=-70.6 \mathrm{~kJ} / \mathrm{mol} ; \Delta \mathrm{G}=-82.5 \mathrm{~kJ} / \mathrm{mol}
$$




$$
\begin{gathered}
F B \quad \mathrm{Co}_{3} \mathrm{O}_{4}(\mathrm{~s})+\mathrm{H}_{2(\mathrm{~g})} \rightarrow 3 \mathrm{CoO}(\mathrm{s}) \\
B A \mathrm{H}_{2} \mathrm{O}_{(\mathrm{g})}, \Delta \mathrm{H}=-39.6 \mathrm{~kJ} / \mathrm{mol} ; \Delta \mathrm{G}=-82.3 \mathrm{~kJ} / \mathrm{mol} \\
B A \quad 3 \mathrm{CoO}_{(\mathrm{s})}+3 \mathrm{H}_{2}(\mathrm{~g}) \rightarrow 3 \mathrm{Co}(\mathrm{s})+3 \mathrm{H}_{2} \mathrm{O}_{(\mathrm{g})}, \Delta \mathrm{H}=-31.0 \mathrm{~kJ} / \mathrm{mol} ; \Delta \mathrm{G}=-0.2 \mathrm{~kJ} / \mathrm{mol}
\end{gathered}
$$

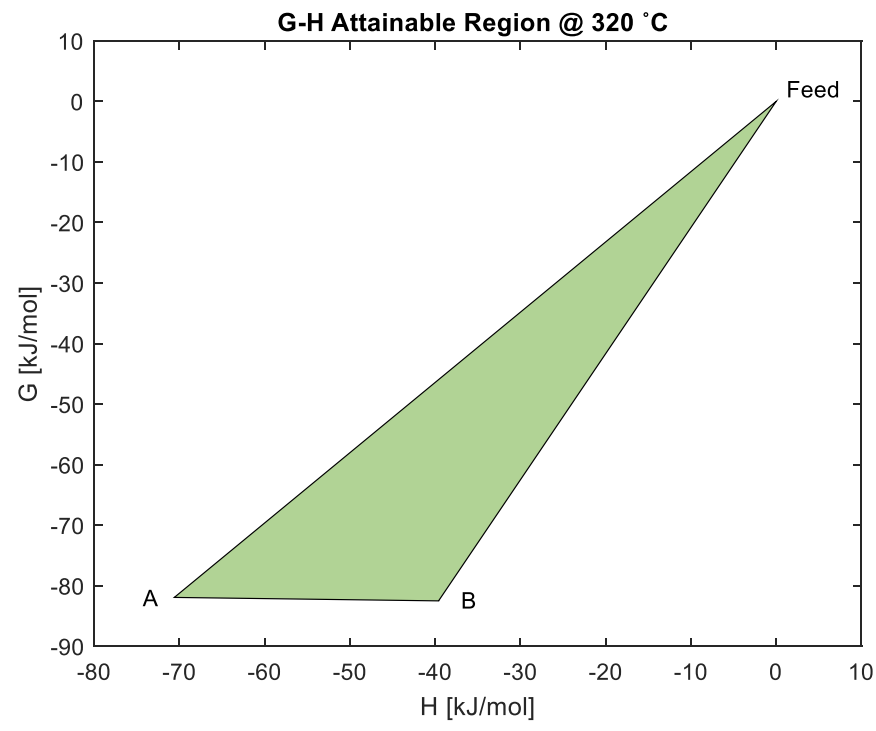

Figure 7. Analysis of predicted material balances using the G-H AR for the cobalt system at $320{ }^{\circ} \mathrm{C}$.

During TPR, the second peak occurs at about $335^{\circ} \mathrm{C}$, which is close to G-H AR at $320^{\circ} \mathrm{C}$ (as shown in Figure 7). It is observed that two possible boundary pathways that convert feed material to different products $(\overrightarrow{F A}$ and $\overrightarrow{F B})$ show similar changes in Gibbs free energy; this implies that both reactions have the same driving force and can occur in parallel. The presence of two material balances/reactions (at minimum $\mathrm{G}$ ) that occur at the same time at $335^{\circ} \mathrm{C}$ may explain the broadness of the second peak. Three material balances $(\overrightarrow{F A} ; \overrightarrow{F B} ; \overrightarrow{B A})$ can contribute to the uptake of $\mathrm{H}_{2}$ and/or the formation of active cobalt $(\mathrm{Co}):(\overrightarrow{F B} ; \overrightarrow{B A})$ for FTS. TS. However, reaction $\overrightarrow{B A}$ may not occur if reactions $\overrightarrow{F A}$ and $\overrightarrow{F B}$ have occurred, since both reactions lead up to minimum $\mathrm{G}$ or state of energy. Alternatively, reaction $\overrightarrow{B A}$ implies that compositions at $A$ and $B$ are actually at the thermodynamic equilibrium, since $\Delta \mathrm{G}_{\mathrm{BA}}=0$. This means that there is likely to be a mixture of products of $\overrightarrow{F A}$ and $\overrightarrow{F B}$ in the final product. Because of this scenario, the resulting reduction of the $\mathrm{CoO}$ to $\mathrm{Co}$ may be misunderstood, with researchers assuming that it is the only pathway to make Co during TPR. The G-H AR indicates that the second peak may be a result of the reduction of both cobalt oxides to Co through material balances $\overrightarrow{F A}$ and $\overrightarrow{B A}$. This may justify the broadness of the second peak seen at about $335^{\circ} \mathrm{C}$ in Figure 2, when both $\mathrm{Co}_{3} \mathrm{O}_{4}$ and $\mathrm{CoO}$ are simultaneously reduced to $\mathrm{Co}$.

However, most researchers have predicted that the formation of active cobalt in the temperature range $200-500{ }^{\circ} \mathrm{C}$ is a result of the second peak during TPR via $\overrightarrow{B A}$. It is observed that the ratio of the second peak to the first peak for the two-step reduction is generally close to $1: 3[2,16]$. This is because, at about $250{ }^{\circ} \mathrm{C}$, the reduction of $\mathrm{Co}_{3} \mathrm{O}_{4}$ to $\mathrm{CoO}$ through material balance $\overrightarrow{F B}$, Equation (15), is possible and may result in Peak 1 . At $335^{\circ} \mathrm{C}, \overrightarrow{F B}$ is now at about minimum $\mathrm{G}$, which results in the spontaneous presence of $\mathrm{CoO}$ in the system. This simultaneously triggers the reaction in $\overrightarrow{B A}$, Equation (16), which is also at minimum G-hence the possibility of Peak 2 occurring. The ratio of $\mathrm{H}_{2}$ consumption in $\overrightarrow{F B}$ : $\overrightarrow{B A}$ is $1: 3$, which correlates well with the observed ratios in literature, thus suggesting $\overrightarrow{F B} A$ as the possible pathway. Again, in trying to decide which reaction pathway may be favoured-either $\overrightarrow{F A}$ or $(\overrightarrow{F B} \rightarrow \overrightarrow{B A})$-we may apply Le-Chatelier's principle that suggests a preference for reaction pathway 
$\overrightarrow{F B}$ to $\overrightarrow{F A}$, because it is less exothermic. This then paves the way for the reaction to happen through pathway $\overrightarrow{B A}$.

The G-H AR at $400{ }^{\circ} \mathrm{C}$ in Figure 8 shows that an increase in temperature continues to favour the reduction of $\mathrm{Co}_{3} \mathrm{O}_{4}$ to $\mathrm{CoO}$, as shown by the material balance $\overrightarrow{F B}$, as the $\Delta \mathrm{G}$ is still negative at minimum G. The reduction of $\mathrm{CoO}$ to Co via reaction $\overrightarrow{B A}$ is no longer feasible, unless work $(\Delta \mathrm{G}=12.2 \mathrm{~kJ} / \mathrm{mol})$ is added to the process. Although reduction of $\mathrm{CO}_{3} \mathrm{O}_{4}$ to $\mathrm{Co}$ is still possible through $\overrightarrow{F A}$, the reduction of $\mathrm{Co}_{3} \mathrm{O}_{4}$ to $\mathrm{CoO}$ becomes most favourable as the material balance $\overrightarrow{F B}$ now exists at minimum $\mathrm{G}$. However, the $\triangle \mathrm{G}$ has become less negative with the increase in temperature; this is also seen in Figure $9 \mathrm{a}, \mathrm{b}$, at $600{ }^{\circ} \mathrm{C}$ and $800{ }^{\circ} \mathrm{C}$, respectively. At $600{ }^{\circ} \mathrm{C}$, the $\Delta \mathrm{G}$ for the material balance $\overrightarrow{F A}$ approaches $\Delta \mathrm{G}=0 \mathrm{~kJ} /$ mole, meaning that reduction to Co is unlikely to occur. This is not favourable for FTS.

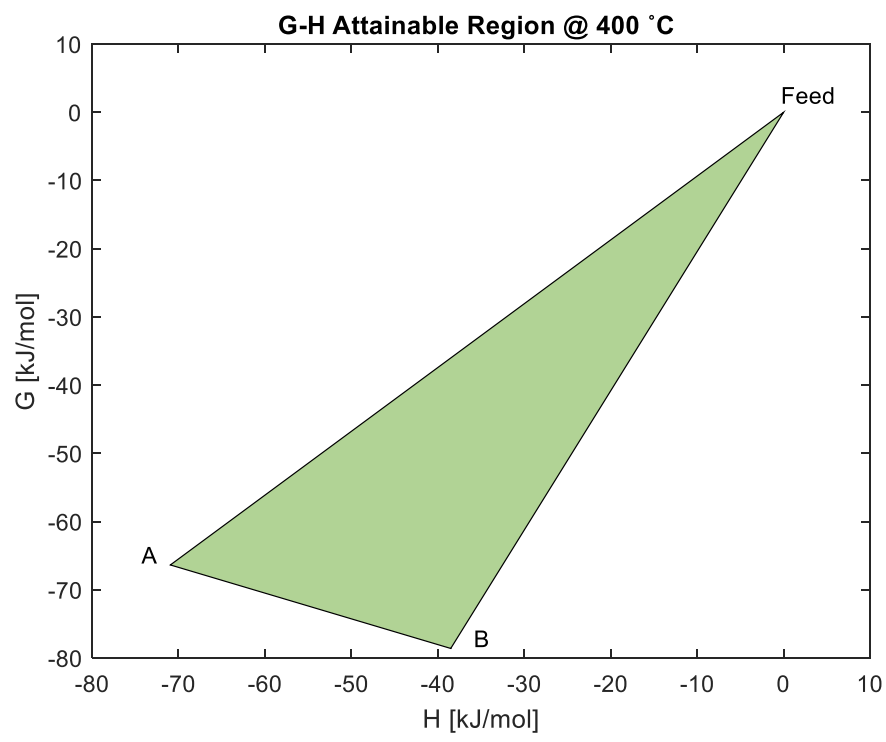

Figure 8. G-H AR for the cobalt system at $400{ }^{\circ} \mathrm{C}$.

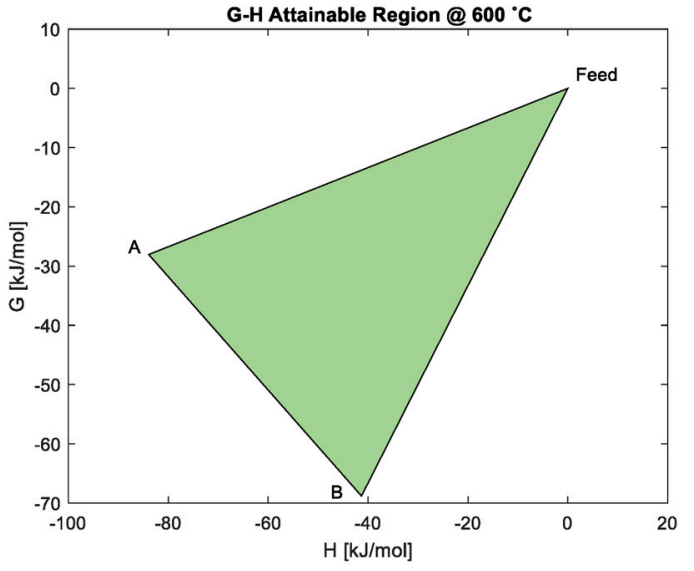

(a)

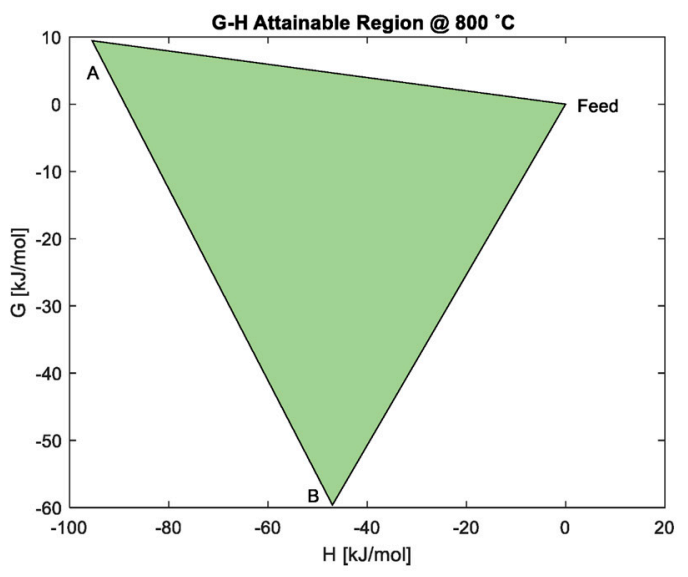

(b)

Figure 9. G-H AR for the cobalt system at: (a) $600{ }^{\circ} \mathrm{C}$; (b) $800{ }^{\circ} \mathrm{C}$.

In this study, the G-H AR showed that when $\mathrm{H}_{2}$ is used to reduce $\mathrm{Co}_{3} \mathrm{O}_{4}$ to $\mathrm{Co}$, this reduction process is not feasible above $600{ }^{\circ} \mathrm{C}$, unless work is added. As the temperature is increased above 
$400{ }^{\circ} \mathrm{C}$, the formation of $\mathrm{CoO}$ will dominate the system at $800{ }^{\circ} \mathrm{C}$ and above. This may also suggest that $\mathrm{CoO}$ may be more stable at high temperatures.

Table 4 gives the thermodynamic data of $\Delta \mathrm{G}$ and $\Delta \mathrm{H}$ for the material balances that form the boundaries of the G-H AR at different temperatures studied at ambient pressure.

\section{Discussion}

\section{What This Means in FTS Application}

The AR has shown that the degree of reduction of $\mathrm{Co}_{3} \mathrm{O}_{4}$ to $\mathrm{Co}$ is a function of temperature. As temperature is increased, the reaction that reduces $\mathrm{Co}_{3} \mathrm{O}_{4}$ to $\mathrm{CoO}$ becomes increasingly more thermodynamic favourable. This is because the $\Delta \mathrm{G}$ for this material balance remains negative as it approaches minimum $\Delta \mathrm{G}$. The $\Delta \mathrm{G}$ for the reactions that form Co become more positive at temperatures above $600{ }^{\circ} \mathrm{C}$. This means that the reduction of $\mathrm{Co}_{3} \mathrm{O}_{4}$ to active $\mathrm{Co}$ in the system occurs at a defined thermodynamic temperature range (about $25-500{ }^{\circ} \mathrm{C}$ ). The AR shows that the TPR profile of $\mathrm{Co}_{3} \mathrm{O}_{4}$ using $\mathrm{H}_{2}$ is a characteristic of the two-stage reduction process, i.e., $\mathrm{Co}_{3} \mathrm{O}_{4} \rightarrow \mathrm{CoO} / \mathrm{Co}$ (between $200{ }^{\circ} \mathrm{C}$ and $300{ }^{\circ} \mathrm{C}$ ), then $\mathrm{Co}_{3} \mathrm{O}_{4} / \mathrm{CoO} \rightarrow \mathrm{Co}$ (between $300{ }^{\circ} \mathrm{C}$ and $400{ }^{\circ} \mathrm{C}$ ). This occurs at a defined temperature range between $\left(200-400{ }^{\circ} \mathrm{C}\right)$ using a $10 \% \mathrm{Co} /$ Zeolite catalyst, as shown in Figure 2. This corroborates the $\mathrm{H}_{2}$ TPR profiles of unsupported $\mathrm{Co}_{3} \mathrm{O}_{4}$ catalyst calcinated at $350{ }^{\circ} \mathrm{C}$ obtained by Olusola and Sudip [17]. However, the AR results cannot reveal whether associated changes in the microstructure of cobalt phases can affect the G-H AR. In addition, the stability region of small metallic cobalt crystallites may differ from the stability region for bulk metallic cobalt, due to the contribution of the surface energy [18].

Thus, with the G-H AR results obtained, the AR can help further explain the analysis indicated by Case 1 and Case 2 in Figure 10 [2]. We see that, in both cases: the first peak ranges between $200^{\circ} \mathrm{C}$ and $420^{\circ} \mathrm{C}$; the second peak ranges between $420^{\circ} \mathrm{C}$ and $800{ }^{\circ} \mathrm{C}$. These temperature ranges are also a function of the catalyst support used-hence, in this analysis, the research focused mainly on the reaction pathway mechanism explained. The first peak in Case 1 shows the reduction process occurring as $\mathrm{Co}_{3} \mathrm{O}_{4} \rightarrow \mathrm{CoO}$, which is a possible pathway, as shown in the $\mathrm{G}-\mathrm{H}$ AR obtained at these temperatures through $\overrightarrow{F B}$. Once more, the results of this study agree with the second stage $\mathrm{CoO} \rightarrow \mathrm{Co},(\overrightarrow{B A})$ of the reduction process in Case 1, which was also observed by Khodakov et al. [19]. It is important to note that the thermodynamic AR tells us that the first peak may also be a result of the material balance in

Equation (15), $\overrightarrow{F B}\left(\mathrm{Co}_{3} \mathrm{O}_{4} \rightarrow \mathrm{Co}\right)$, as observed in Case 2. This observation agrees with the argument provided by Olusola and Sudip [17]. The second peak in Case 2 may result either through $\mathrm{CoO} \rightarrow \mathrm{Co}$ or $\mathrm{Co}_{3} \mathrm{O}_{4} \rightarrow \mathrm{Co}$ or by a combination of both reduction reaction pathways. Overall, the G-H AR has interpreted the TPR patterns to show reduction of either $\mathrm{Co}_{3} \mathrm{O}_{4}$ directly to $\mathrm{Co}$, or the possibility of a series of reduction mechanisms with an intermediate $\mathrm{CoO}$ from $\mathrm{Co}_{3} \mathrm{O}_{4} \rightarrow \mathrm{CoO} \rightarrow \mathrm{Co}$. However, it is necessary to investigate how promoters added to cobalt catalysts affect the AR, but the promoters can only influence the G-H AR if: they are involved in the reduction reactions; and if they change their initial form to an intermediate or new compound during the reduction process. The effect to which the G-H AR change will then depend on the type of metal/ compound making that promotor. 


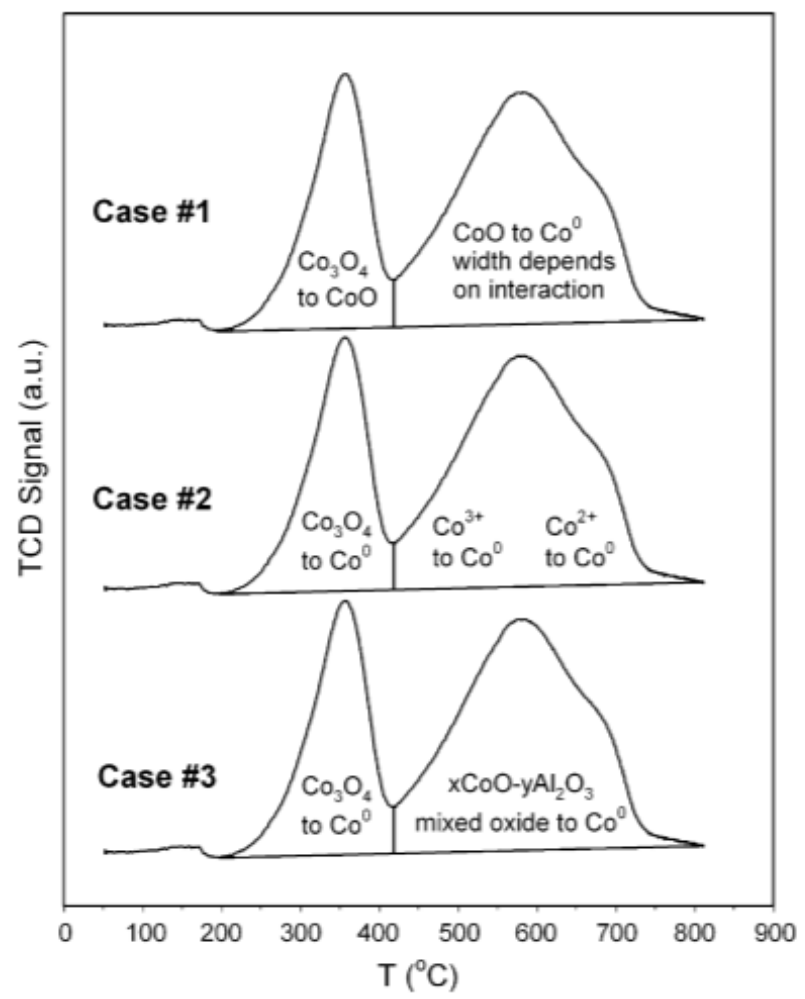

Figure 10. Typical TPR cases analyzed by Jacobs et al. [2].

\section{Conclusions}

The AR technique was effectively applied to better understand catalyst reduction by applying the Gibbs free energy $(G)$ minimization approach, as depicted in the AR space. These AR spaces can predict the cobalt phase for any given reduction condition in the reactor. This thermodynamic tool is useful for predicting optimum temperatures for a desired phase. This study of using AR has revealed a different interpretation of the hydrogen TPR mechanism of cobalt catalysts in FT. It has shown that there are two possible reaction pathways: one that reduces $\mathrm{Co}_{3} \mathrm{O}_{4}$ directly to $\mathrm{Co}$, and another that has $\mathrm{CoO}$ as an intermediate step. The G-H AR tend to show that the reaction pathway $\mathrm{Co}_{3} \mathrm{O}_{4} \rightarrow \mathrm{CoO} \rightarrow$ $\mathrm{Co}$ is thermodynamically favourable during the TPR process. This revelation of the cobalt reduction pathways using $\mathrm{H}_{2}$ can help improve the design of supported cobalt-based FTS catalysts, as researchers can work on a specific reaction pathway to achieve the Co active state.

Supplementary Materials: The following are available online at http://www.mdpi.com/2624-781X/1/2/10/s1. Document 1.

Author Contributions: Conceptualization: J.G. and R.M. Methodology: J.G., R.M. and E.L. Software: R.M. Validation: R.M., E.L. and D.H. Formal analysis, E.L. Investigation: D.H. Resources: D.H. Data curation: R.M. Writing-original draft preparation: R.M. and J.G. Writing—review and editing: J.G. Visualization: E.L. Supervision: D.H. Project administration: J.G. Funding acquisition: D.H. All authors have read and agreed to the published version of the manuscript.

Funding: This research received no external funding.

Acknowledgments: The authors are grateful for the support provided by the University of South Africa (UNISA), the National Research Foundation (NRF) of South Africa and the Institute for the Development of Energy for African Sustainability (IDEAS) at UNISA.

Conflicts of Interest: The authors declare no conflict of interest. 


\section{References}

1. Gorimbo, J. Use of Stability Diagrams to Predict Catalyst Speciation during Fischer Tropsch Reduction stage: A Mini-Review. Catal. Sci. Technol. 2018, 8, 2022-2029. [CrossRef]

2. Jacobs, G.; Ji, Y.; Davis, B.H.; Cronauer, D.; Kropf, A.J.; Marshall, C.L. Fischer-Tropsch Synthesis: Temperature Programmed EXAFS/XANES Investigation of the Influence of Support Type, Cobalt Loading, and Noble Metal Promoter Addition to the Reduction Behavior of Cobalt Oxide Particles. Appl. Catal. A Gen. 2007, 333, 177-191. [CrossRef]

3. Kumar, N.; Payzant, E.A.; Jothimurugesan, K.; Spivey, J.J. Combined in Situ XRD and in Situ XANES Studies on the Reduction Behavior of a Rhenium Promoted Cobalt Catalyst. Phys. Chem. Chem. Phys. 2011, 13, 14735-14741. [CrossRef]

4. Phaahlamohlaka, T.N.; Kumi, D.O.; William, M.; Forbes, R.; Jewell, L.L.; Billing, D.G.; Coville, N.J. Effects of Co and Ru intimacy in Fischer-Tropsch Catalysts Using Hollow Carbon Sphere Supports: Assessment of the Hydrogen Spillover Processes Effects of Co and Ru Intimacy in Fischer-Tropsch Catalysts Using Hollow Carbon Sphere Supports: Assessment of. ACS Catal. 2016, 7, 1568-1578. [CrossRef]

5. Sempuga, B.C.; Hausberger, B.; Patel, B.; Hildebrandt, D.; Glasser, D. Classification of Chemical Processes: A graphical Approach to Process Synthesis to Improve Reactive Process Work Efficiency. Ind. Eng. Chem. Res. 2010, 49, 8227-8237. [CrossRef]

6. Hildebrandt, D.; Glasser, D.; Crowe, C.M. Geometry of the Attainable Region Generated by Reaction and Mixing: With and without Constraints. Ind. Eng. Chem. Res. 1990, 29, 49-58. [CrossRef]

7. Patel, B. Fundamental Targets for the Synthesis and Evaluation of Chemical Processes. Ph.D. Thesis, University of the Witwatersrand, Johannesburg, South Africa, 2007.

8. Qiao, Z.; Wang, Z.; Zhang, C.; Yuan, S.; Zhu, Y.; Wang, J. PVAm-PIP/PS Composite Membrane with High Performance for $\mathrm{CO}_{2} / \mathrm{N}_{2}$ Separation. AIChE J. 2012, 59, 215-228. [CrossRef]

9. Okonye, L.U.; Hildebrandt, D.; Glasser, D.; Patel, B. Attainable Regions for a Reactor: Application of $\Delta \mathrm{H}-\Delta \mathrm{G}$ Plot. Chem. Eng. Res. Des. 2012, 90, 1590-1609. [CrossRef]

10. Yin, F. A Simpler Method for Finding Independent Reactions. Chem. Eng. Commun. 1989, 83, 117-127. [CrossRef]

11. Chase, M.W., Jr. NIST-JANAF Themochemical Tables, 4th ed.; NIST: Gaithersburg, MD, USA, 1998. [CrossRef]

12. UCDSB. Available online: http://Www2.Ucdsb.on.ca/Tiss/Stretton/Database/Inorganic_thermo.Htm (accessed on 27 September 2020).

13. Holmes, R.D.; O'Neill, H.S.C.; Arculus, R.J. Standard Gibbs Free Energy of Formation for $\mathrm{Cu}_{2} \mathrm{O}, \mathrm{NiO}, \mathrm{CoO}$, and FexO: High Resolution Electrochemical Measurements Using Zirconia Solid Electrolytes from 900-1400 K. Geochim. Cosmochim. Acta 1986, 50, 2439-2452. [CrossRef]

14. Du Plessis, H.E.; Forbes, R.P.; Barnard, W.; Erasmus, W.J.; Steuwer, A. In Situ Reduction Study of Cobalt Model Fischer-Tropsch Synthesis Catalysts. Phys. Chem. Chem. Phys. 2013, 15, 11640-11645. [CrossRef]

15. UCDSB. Inorganic Compounds: Physical and Thermochemical Data. Available online: http://www2.ucdsb. on.ca/tiss/stretton/database/inorganic_thermo.htm (accessed on 15 September 2020).

16. Lin, H.Y.; Chen, Y.W. The Mechanism of Reduction of Cobalt by Hydrogen. Mater. Chem. Phys. 2004, 85, 171-175. [CrossRef]

17. Olusola, O.J.; Sudip, M. Temperature Programme Reduction (TPR) Studies of Cobalt Phases in Alumina Supported Cobalt Catalysts. J. Pet. Technol. Altern. Fuels 2016, 7, 1-12. [CrossRef]

18. Van Steen, E.; Claeys, M.; Dry, M.E.; Van De Loosdrecht, J.; Viljoen, E.L.; Visagie, J.L. Stability of Nanocrystals: Thermodynamic Analysis of Oxidation and Re-Reduction of Cobalt in Water/Hydrogen Mixtures. J. Phys. Chem. B 2005, 109, 3575-3577. [CrossRef] [PubMed]

19. Khodakov, A.Y.; Lynch, J.; Bazin, D.; Rebours, B.; Zanier, N.; Moisson, B.; Chaumette, P. Reducibility of Cobalt Species in Silica-Supported Fischer-Tropsch Catalysts. J. Catal. 1997, 168, 16-25. [CrossRef]

Publisher's Note: MDPI stays neutral with regard to jurisdictional claims in published maps and institutional affiliations. 